\title{
$\operatorname{con} 8.951073-6$ \\ WHC-SA-2861-FP
}

\section{A Method to Improve Spectral Resolution in Planar Semiconductor Gamma-Ray Detectors}

\section{DISCLAIMER}

This report was prepared as an account of work sponsored by an agency of the United States Government. Neither the United States Government nor any agency thereof, nor any of their employees, makes any warranty, express or implied, or assumes any legal liability or responsibility for the accuracy, completeness, or usefulness of any information, apparatus, product, or process disclosed, or represents that its use would not infringe privately owned rights. Reference herein to any specific commercial product, process, or service by trade name, trademark, manufacturer, or otherwise does not necessarily constitute or imply its endorsement, recommendation, or favoring by the United States Government or any agency thereof. The views and opinions of authors expressed herein do not necessarily state or reflect those of the United States Government or any agency thereof.

Prepared for the U.S. Department of Energy

Office of Environmental Restoration and

Waste Management

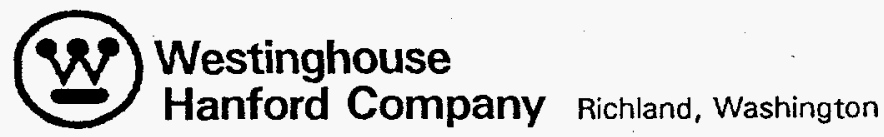

Hanford Operations and Engineering Contractor for the

U.S. Department of Energy under Contract DE-ACO6-87RL10930

Copyright License By acceptance of this article, the publisher and/or recipient acknowledges the

U.S. Government's right to retain a nonexclusive, royalty-free license in and to any copyright covering this paper.

DISTRIBUTION OF THIS DOCUMENT IS UNLIMITED

I) Approved for Public Release 


\section{LEGAL DISCLAIMER}

This report was prepared as an account of work sponsored by an agency of the United States Government. Neither the

United States Government nor any agency thereof, nor any of their employees, nor any of their contractors, subcontractors or their employees, makes any warranty, express or implied, or assumes any legal liability or responsibility for the accuracy, completeness, or any third party's use or the results of such use of any information, apparatus, product, or process disclosed, or represents that its use would not infringe privately owned rights. Reference herein to any specific commercial product, process, or service by trade name, trademark, manufacturer, or otherwise, does not necessarily constitute or imply its endorsement, recommendation, or favoring by the United States Government or any agency thereof or its contractors or subcontractors. The views and opinions of authors expressed herein do not necessarily state or reflect those of the United States Government or any agency thereof.

This report has been reproduced from the best available copy.

Printed in the United States of America

DISCLM-2.CHP (1-91) 


\section{DISCLAIMER}

Portions of this document may be illegible in electronic image products. Images are produced from the best available original document. 


\section{A Method to Improve Spectral Resolution in Planar Semiconductor Gamma-Ray Detectors}

B. D. Keele

R. S. Addleman

G. L. Troyer

Date Published

May 1995

To Be Presented at 1995 IEEE Nuclear Science

Symposium

October 21-27, 1995

San Francisco, California

Prepared for the U.S. Department of Energy Office of Environmental Restoration and Waste Management

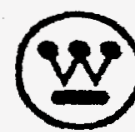

Westinghouse

P.O Box 1970

Hanford Company Richland, Washington

Hanford Operations and Engineering Contractor for the

U.S. Department of Energy under Contract DE-ACO6-87RL10930

Copyright License By acceptance of this article, the publisher and/or recipient acknowledges the

U.S. Government's right to retain a nonexclusive, royalty-free license in and to any copyright covering this paper. 


\title{
A Method to Improve Spectral Resolution in Planar Semiconductor Gamma-Ray Detectors.
}

\author{
B.D. Keele* \\ International Technology Hanford Company, \\ Richland WA, 99352
}

R.S. Addleman and G.L. Troyer, Westinghouse Hanford Company, P.O. Box 1970, Richland WA, 99352.

For publication in IEEE Transactions on Nuclear Science.

\section{Abstract}

This paper describes an empirically derived algorithm to compensate for charge trapping in CdTe, CdZnTe, and other planar semiconductor detectors. The method is demonstrated to be an improvement over available systems and application to experimental data is shown.

\section{INTRODUCTION}

Small CdTe and CdZnTe detectors are utilized for gamma-ray spectroscopy in high activity environments where the space is limited, cooling is inconvenient, and a rugged detector is desirable.

Charges are often trapped within these high $Z$ semiconductor detectors following a gamma-ray interaction. This results in an event pulse with an amplitude that is smaller than events that occur without charge trapping. The overall result is severe photopeak tailing in the gamma-ray energy spectrum.

The event pulse risetime can be used as a measure of the charge trapping that occurs within the detector. An event with a large degree of charge trapping will have an output pulse with a long risetime. Events with less charge trapping have shorter risetimes.

Pulse shape discrimination (PSD) is a technique in which only those pulses that lie within a narrow range of risetimes are accepted for counting. It has been shown that the resulting spectrum has greatly improved resolution at the expense of rejecting a large fraction of the events ${ }^{1-3}$. Fig. 1 depicts the electronic configuration of a PSD system.

\footnotetext{
Author to whom correspondance should be directed.

Present address is 504 Bobolink Rd, Knoxville, TN 37922
} 


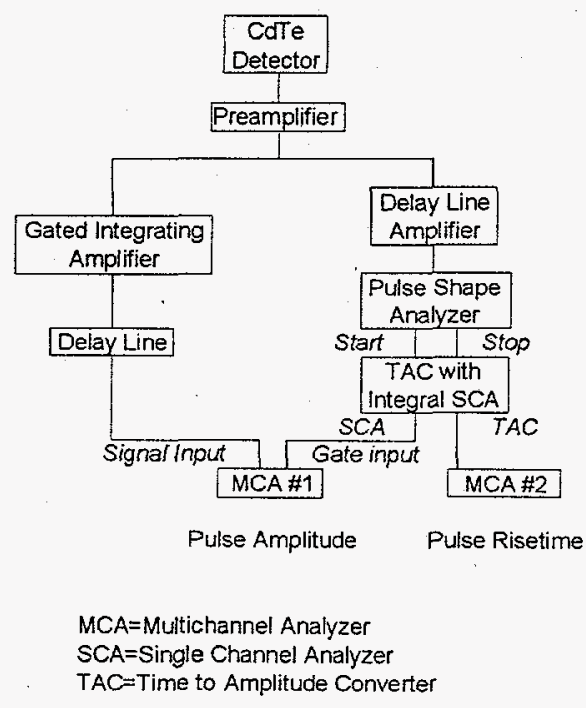

Figure 1. Block Electronics.

Fig. 2 depicts a typical risetime distribution of a gamma-ray source illuminating a CdTe detector.

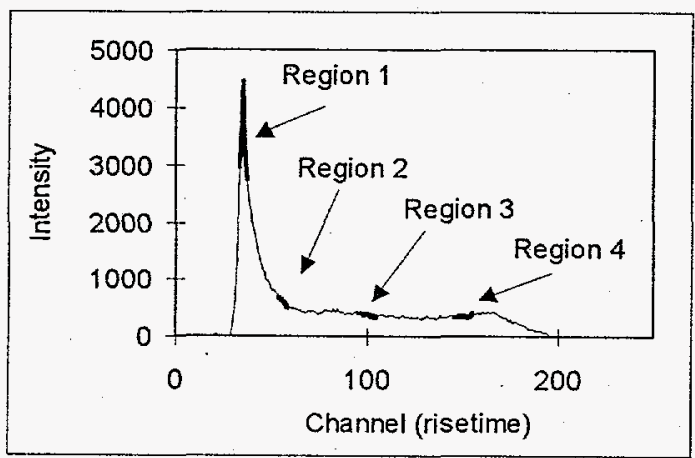

Figure 2. Typical risetime distribution. The highlighted regions depict the range of pulses accepted for counting in acquiring the spectra for Figs. 3 and 4.

Fig. 3 depicts a Cs-137 gamma energy spectrum in which the pulses from region \#1 in Fig. 2 are accepted for counting. The increased spectral resolution with
PSD is clearly shown. The shoulder on the low energy side (left) of the peak in the PSD spectra are the Cd and Te $\mathrm{x}$-ray escape peaks. By narrowing the acceptance window spectral resolution can be improved at the cost of rejecting a larger portion of the pulses.

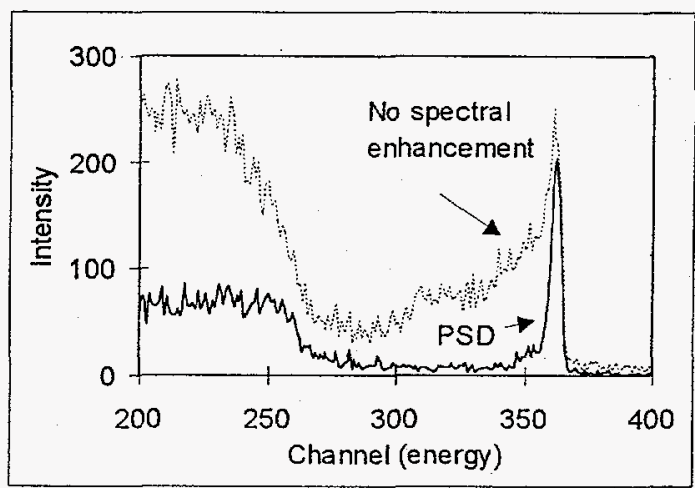

Figure 3. $\mathrm{Cs}^{137}$ spectra which depict improved resolution and loss of efficiency from the use of pulse shape discrimination (PSD). Pulses were accepted from risetime region \#1 from Fig. 2.

Any narrow region of the risetime distribution selected for counting results in a gamma-ray spectrum with distinct photopeaks. Fig. 4 shows gamma-ray photopeaks from the different risetime regions indicated in Fig. 2. Pulses that are selected from longer risetimes are shifted to lower channel due to increased charge trapping. Acceptance regions at longer risetimes also produce photopeaks of relative lower intensity. This can be seen in Fig. 4 with the region 1 photopeak area over five times those from regions $2-4$. 


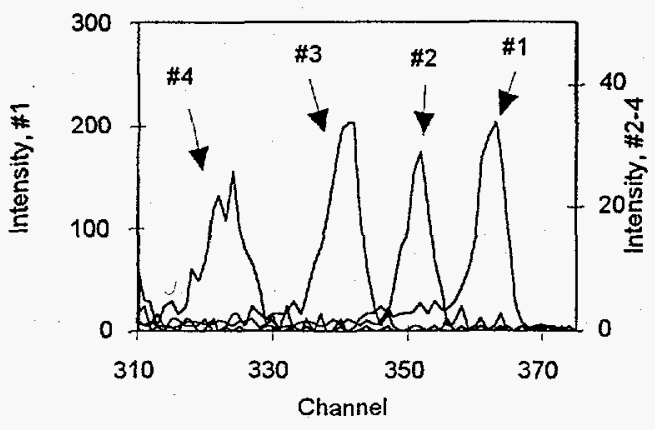

Figure 4. $\mathrm{Cs}^{137}$ photopeaks in spectra that result from correspondingly numbered risetime regions in Fig. 2.

Alternatively, pulse risetime compensation ${ }^{1}$ (PRC) is a technique by which the amplitude of each pulse is adjusted by an amount dependent upon the pulse risetime, so that the effects of charge trapping are partially overcome ${ }^{1,4-7}$. The technique counts every event while maintaining resolution that is satisfactory for most applications.

An EG\&G ORTEC instrument, model \#675, based on the works of Goulding and Landis ${ }^{4}$, and the work of Simpson et.al. ${ }^{5}$, has been used routinely at Westinghouse Hanford Company ${ }^{1,7}$. The instrument effectively multiplies the pulse amplitude by a function of the risetime squared. The method is sometimes combined with a PSD system to reject some of the longer rising pulses. Gamma-ray spectra taken with the instrument are a large improvement over an uncompensated spectrum, even though ideally shaped gaussian photopeaks are not obtained. Some photopeak tailing is still observed and it is believed that these shortcomings arise because the instrument was designed for coaxial detectors, not planar detectors.

Other commercially available electronic modules have been developed for planar semiconductor detectors that produce an output pulse that is a function of both the input pulse risetime and amplitude. Unfortunately, application experience with these instruments modules was not successful.

A more accurate method to compensate for charge trapping is presented below. The developed algorithm compensates all pulses to a hypothetical zero risetime corresponding to zero charge trapping.

\section{DEVELOPMENT OF PRC ALGORITHM}

The method was developed experimentally from gamma-ray sources illuminating a $2 \times 2 \times 2 \mathrm{~mm}$ $\mathrm{CdTe}$ detector using the PSD instrumentation depicted in Fig. 1. $\mathrm{Co}^{60}$ and $\mathrm{Ra}^{226}$ sources were counted in a manner similar to the development of Fig. 4.

Fig. 5 is a plot of pulse risetime versus resulting photopeak centroid for the some of the major photopeaks. 


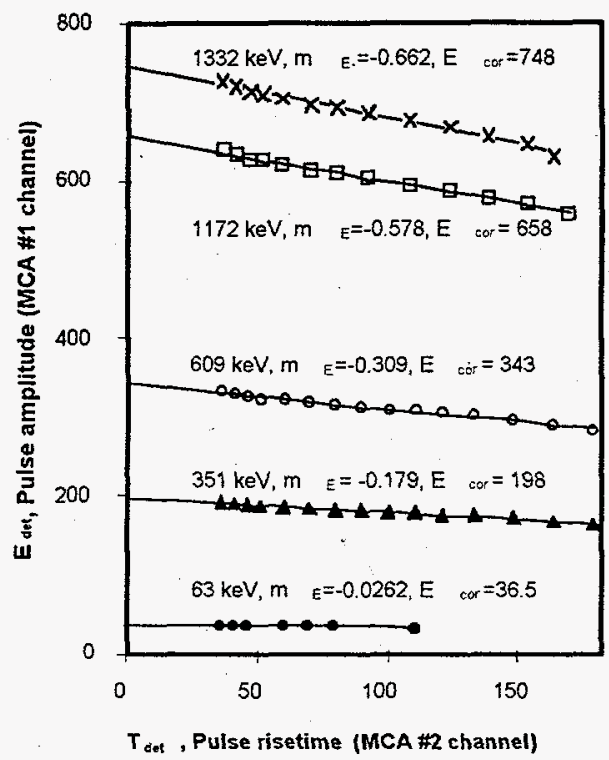

Figure 5. Pulse Risetime vs. resulting photopeak centroid. $E_{\text {cor }}$ and $m_{E}$ are the $y$-intercept and the slope of each line, respectively.

As shown in Fig. 5 data can be well fit by a straight line with a different slope for each gamma energy. The linear equation for the graphs in Fig. 5 is:

$$
E_{\text {det }}=m_{E} T_{\text {det }}+E_{c o r} .
$$

$E_{\text {det }}$ is the amplitude of the detector output voltage measured as MCA \#1 channel numbers. $m_{E}$ is the slope of each line in Fig. 5. $T_{\text {det }}$ is the risetime of the detector output measured as MCA \#2 channel numbers, and $E_{\text {cor }}$ is a channel number corresponding to the $y$ intercept of each line. The corrected pulse energy, $E_{c o r}$ is the desired pulse amplitude for an incident photon. $E_{\text {cor }}$ is the result of adjusting $E_{\text {det }}$ to an idealized point of zero risetime with no corresponding charge trapping.

The slope of each line in Fig. $5, m_{E}$, is a linear function of the gamma-ray energy. Fig. 6 represents a plot of the gamma-ray energy versus $m_{E}$.

The equation of the fitted line is:

$$
m_{E}=k_{1} E_{g a m m a}+k_{2}
$$

where $k_{1}$ is the slope in Fig. 6, $k_{2}$ is the intercept constant, and $E_{\text {gamma }}$ is the incident gamma-ray energy.

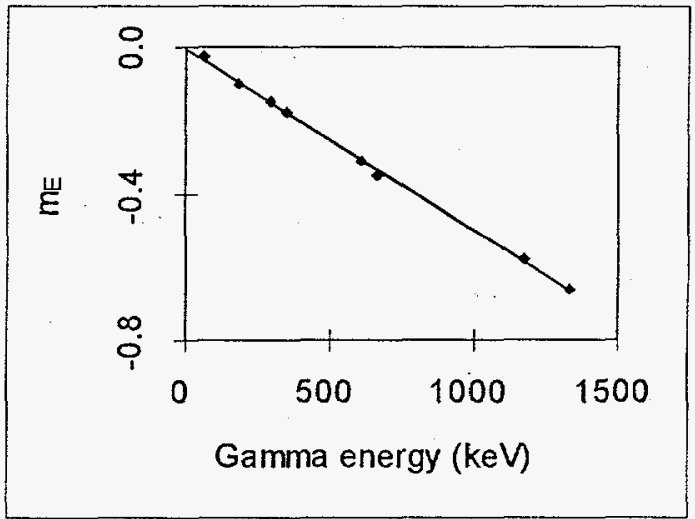

Figure 6. Gamma-ray energy vs. $m_{E}$. The slope $=-4.94 E-04$ and $y-$ intercept $=-5.21 \mathrm{E}-03$, which are the constants, $k_{1}$ and $k_{2}$, respectively.

The ideal output pulse, $E_{c o r}$ in Fig. 5 , is also related to the energy of the incident gamma-ray, $E_{\text {gamma }}$ through the energy calibration of the system. Fig. 7 is a plot of gammaray energy versus $E_{\text {cor }}$. 


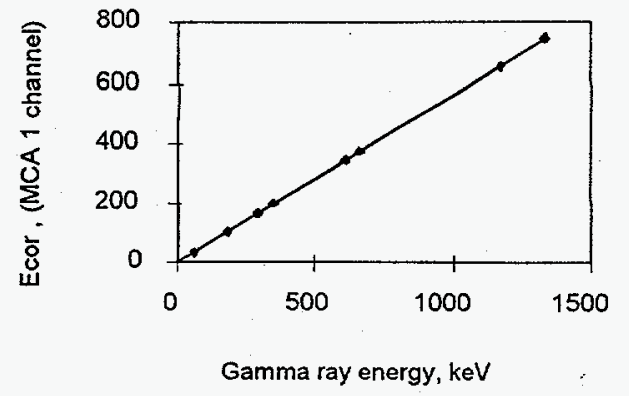

Figure 7. Gamma-ray energy versus $E_{\text {cor }}$. The slope $=0.5609$ and $y$-intercept $=1.301$, are the constants $k_{3}$ and $k_{4}$, respectively.

The equation of the fitted line is:

$$
E_{c o r}=k_{3} E_{\text {gamma }}+k_{4}
$$

where $k_{3}$ is a constant with units of channels/photon energy representing the overall system gain, and $\mathrm{k}_{4}$ is a constant with units of channels representing the zero offset.

The combination of equations 2 and 3 yields:

$$
m_{E}=k_{1}\left(E_{c o r}-k_{4}\right) / k_{3}+k_{2}
$$

re-arranging and simplifying yields:

$$
m_{E}=A E_{c o r}+B
$$

where $\mathrm{A}$ and $\mathrm{B}$ are combination constants.

The combination of equations 1 and 5 yields:

$$
E_{\text {det }}=T_{\text {det }}\left(A E_{c o r}+B\right)+E_{c o r}
$$

Re-arranging and solving for $\mathrm{E}_{\text {cor }}$ yields:

$$
E_{c o r}=\left(E_{\text {det }}-B T_{\text {det }}\right) /\left(1+A T_{\text {det }}\right)
$$

Equation 7 represents an algorithm for which pulses originating from planar semiconductor detectors may be adjusted on the basis of both their amplitude and risetime to produce a pulse which is compensated for the effects due to charge trapping.

For example, the detector depicted in Figs. 5-7 has the constants with the values: $A=-8.807 \mathrm{E}-04$; and $B=$ $6.25 \mathrm{E}-03$. Thus, if a single pulse has an amplitude of $E_{\text {det }}=$ channel 346 and with a risetime of $\mathrm{T}_{\text {det }}=$ channel 80 , then the overall corrected pulse would have a value of channel 371.7 .

In summary, a corrected gamma-ray energy, $E_{c o r}$, can be determined utilizing the detector pulse amplitude, $E_{\text {det, }}$ pulse risetime, $T_{\text {det, }}$ and two empirically determined constants, $\mathrm{A}$ and $\mathrm{B}$. A and $\mathrm{B}$ are detector specific and independent of gamma-ray energy.

\section{PRC METHOD VALIDATION AND RESULTS}

To support the validity of the model, additional gamma-ray sources were counted repetitively. Using the described PSD system, a narrow window of risetimes was accepted for counting in each spectrum. The window was moved across the entire risetime spectrum, so that each successive gamma-ray energy spectrum came from a successively 
longer risetime. A simple sum of all spectra would be equivalent to a single spectrum that was derived from all risetimes. Spectral data was manipulated in a spreadsheet using the described model to generate a PRC enhanced spectra.

Fig. 8 shows the effect of PRC on a $\mathrm{Cs}^{137}$ spectrum. Only the longest rising pulses (less than 5\%) were rejected and not analyzed in order to improve the spectral quality.

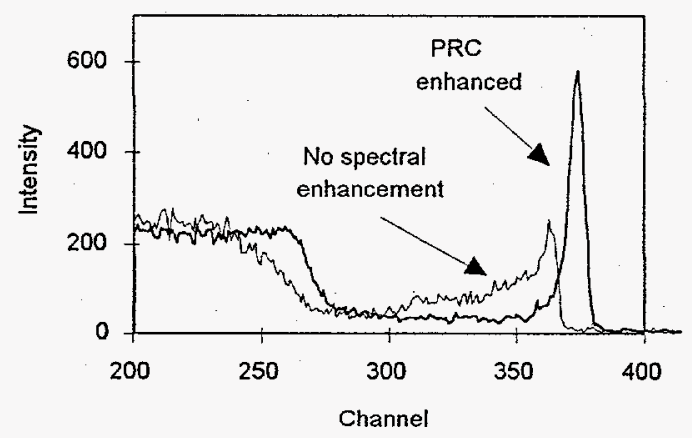

Figure 8. $\mathrm{Cs}^{137}$ spectra using pulse risetime compensation (PRC). Note that alignment of all pulses based on the risetime improves the peak resolution and correspondingly increases the peak height.

$A \mathrm{Eu}^{154}$ source was counted and manipulated in the same manner.

Fig. 9 is the resulting spectrum showing the model was successful at improving spectral photopeaks over a large range of energies. The slight amount of low energy tailing that remains may be due to the large width of the risetime window that was used in acquiring the individual spectra that comprise the overall spectrum.

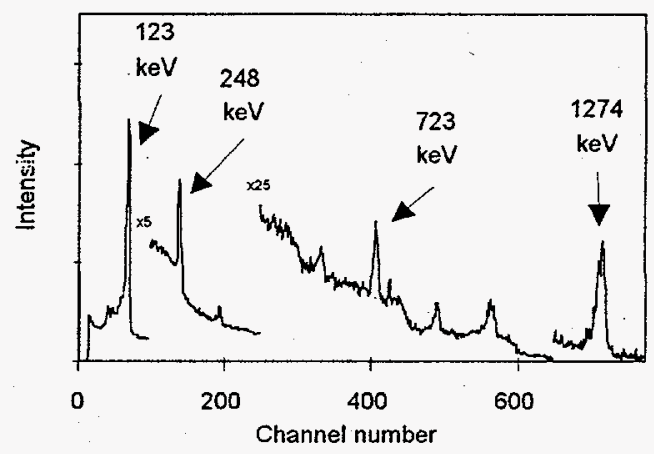

Figure 9. $\mathrm{Eu}^{154}$ spectrum showing the effect of compensation over a large range of energies.

\section{CONCLUSIONS}

In summary, a new PRC algorithm has been developed to compensate for charge trapping in planar semiconductor detector;

$$
E_{c o r}=\left(E_{\text {det }}-B T_{\text {det }}\right) /\left(1+A T_{\text {det }}\right) \text {. }
$$

The corrected gamma-ray energy, $E_{c o r}$ can be determined with the detector pulse amplitude; $E_{\text {det, }}$ pulse risetime, $T_{\text {det, }}$ and two empirically determined constants, $A$ and $B$. A and $B$ are optimized for each detector and valid over the entire spectral range.

It has been shown that PRC can approach PSD in spectral resolution without discarding the majority of the pulses. PRC can be performed in real-time with analog electronic modules or after data collection. No electronic modules using the PRC method discussed in this paper are 
presently available. However, development of a system utilizing the PRC algorithm described herein would allow relatively high resolution spectra to be efficiently collected from small, inexpensive, room temperature, high Z planar semiconductor detectors.

\section{REFERENCES}

${ }^{1}$ R.S. Addleman, G.R. Blewett, B.D. Keele, C.S. McClellan, V.B. Subrahmanyam, G.L. Troyer, "Application of a CdTe Gamma-Ray Spectrometers to Remote Characterization of High-Level Radioactive Waste Tanks," Proceedings of the 1991 IEEE Nuclear Science Symposium, Santa Fe, New Mexico, Nov. 5-9, 1991.

${ }^{2}$ L.T. Jones and P.B. Woolam, "Resolution Improvements in CdTe Gamma Detectors Using Pulse-Shape Discrimination," Nuclear Instruments and Methods, Vol. 124, pp. 591-595, 1975.

${ }^{3}$ L.T. Jones, "The use of Cadmium Telluride Gamma Spectrometers in Monitoring Activity Deposited in Nuclear Power Stations," Revue De Physique Appliquee, Vol. 12, No. 2, pp. 379-384, Feb. 1977.

${ }^{4}$ F.S. Goulding and D.A. Landis, "Ballistic Deficit Correction in Semiconductor Spectrometers," IEEE Transactions on Nuclear Science, Vol. 35, No. 1, pp. 119124, Feb 1988.

${ }^{5}$ M.L. Simpson, T.W. Raudorf, T.J. Paulus, and R.C. Trammel, "Charge Trapping Correction in Ge Spectrometers," IEEE Transactions on Nuclear Science, Vol. 36 , No. 1, Feb. 1989.

${ }^{6}$ M. Richter, P. Siffert, "High Resolution Spectrometery with CdTe Detector Systems," 7th Internat. Workshop on Room Temperature $X$ - and Gamma- Ray Detectors, Ravello, Italy, Sept. 23-28, 1991.
7 B.D. Keele, R.S. Addleman, M.A. Beck, G.R. Blewett,"Remote Nuclear Screening System for Hostile Environments," Nuclear Instruments and Methods in Physics Research, Section A, submitted for publication. 